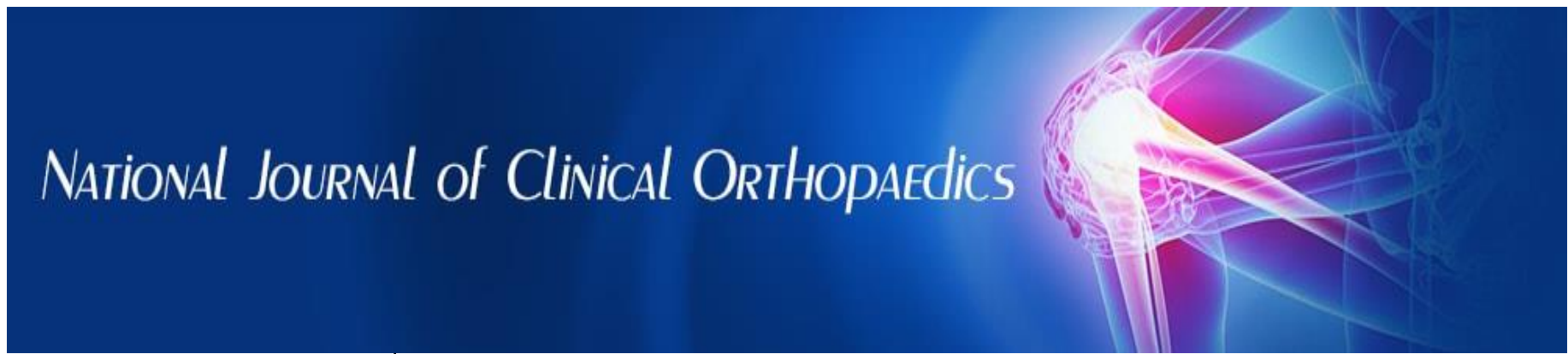

ISSN (P): 2521-3466

ISSN (E): 2521-3474

(C) Clinical Orthopaedics

www.orthoresearchjournal.com

2021; 5(2): 12-15

Received: 16-12-2020

Accepted: 19-01-2021

Dr. Eknath D Pawar

Professor and Head of department,

Department of Orthopaedic, Grant Govt. Medical College \& Sir JJ Group of Hospitals Mumbai, India

\section{Dr. Akshay KS}

Junior Resident, Department of Orthopaedic, Grant Govt. Medical College \& Sir JJ Group of Hospitals Mumbai, India

\section{Dr. Nadir Z Shah}

Associate Professor, Department of Orthopaedic, Grant Govt. Medical College \& Sir JJ Group of Hospitals Mumbai, India

Dr. Amit Kumar Yadav

Assistant Professor, Department of Orthopaedic, Grant Govt. Medical College \& Sir JJ Group of Hospitals Mumbai, India

\section{Dr. Sagar Bansal}

Junior resident, Department of Orthopaedic, Grant Govt. Medical College \& Sir JJ Group of Hospitals Mumbai, India

Dr. Angad Ravindra Chikodi Junior resident, Department of Orthopaedic, Grant Govt. Medical College \& Sir JJ Group of Hospitals Mumbai, India
Corresponding Author: Dr. Akshay KS Junior Resident, Department of Orthopaedic, Grant Govt. Medical College \& Sir JJ Group of Hospitals Mumbai, India

\section{Functional outcome of distal third Metaphyseal Tibial fractures operated with reamed Intramedullary Tibia Nailing: Two versus three distal locking screws}

\author{
Dr. Eknath D Pawar, Dr. Akshay KS, Dr. Nadir Z Shah, Dr. Amit Kumar \\ Yadav, Dr. Sagar Bansal and Dr. Angad Ravindra Chikodi
}

DOI: https://doi.org/10.33545/orthor.2021.v5.i2a.275

\begin{abstract}
Introduction: Fractures of the distal metaphysis of the tibia can be nailed if a sufficient amount of bone is available distal to the fracture site to insert two or three locking screws. However, fractures in this region operated with nail fixation provide less stability as a result of metaphyseal flare, which reduces the contact between the nail and the endosteal surface.

Aim: The purpose of this retrospective study was to assess the union and complications associated with distal third tibial fractures which were operated with reamed tibia nail with two versus three distal locking screws.

Materials \& Methods: The study was carried out between 2017-2019 in which fifty-seven patients were included in the study. In 25 patients 2 distal screws were inserted and in 32 patients 3 distal screws. Patients were followed up to the tibial fracture union (5-12 months with a mean of 7 months).

Results: Our results showed, $4 \%$ of delayed unions in distal third fractures with two distal screws compared to $3.12 \%$ who had three distal screws. This is statistically insignificant $(\mathrm{p}>0.01)$. None of the patients developed non-union nor had screw breakage and residual ankle or knee pain.

Conclusion: Our study showed that there was no statistically significant difference in the time taken for radiographic union and complications such as delayed union and non-union in distal third tibia fractures operated with tibia nailing when two or three distal locking screws were used. Therefore, we conclude that two distal locking screws are a necessity and three are a luxury. The increased distal locking screws
\end{abstract} do not influence the fracture union.

Keywords: Distal tibial fractures, two vs three, distal locking screws, fracture union, complications

\section{Introduction}

Displaced fractures of the tibial diaphysis are often best operated with reamed or unreamed intramedullary nailing (IMN) ${ }^{[1-3]}$. On the other hand, distal tibia metaphyseal fractures have been treated successfully by various methods of fixation ${ }^{[4-5]}$. These fractures can be operated with intramedullary nailing if a sufficient amount of bone is available distal to the fracture site to insert two or three locking screws. However, fractures in this region operated with nail fixation provide less stability as a result of metaphyseal flare, which reduces the contact between the nail and the endosteal surface. Advances in nail design, especially the presence of different distal locking options with multiplanar fixation configurations, have improved the biomechanics of fixation of distal tibia fractures. Improvements in nail design also include the ability to use larger interlocking screws without compromising the strength of the nail at the screw hole ${ }^{[6]}$. Thus, it is now possible for nails with a small diameter of $10 \mathrm{~mm}$ to have interlocking screws with a $5 \mathrm{~mm}$ outer diameter. Biomechanical work has proved that compared with smaller diameter screws, newer screws larger than $4.5 \mathrm{~mm}$ in outer diameter can withstand greater forces without fatigue breakage ${ }^{[6]}$. However, as the indications for IM fixation have been extended to include proximal and distal extra-articular tibial fractures ${ }^{[7-9]}$, malalignment and loss of reduction become a concern ${ }^{[10-12]}$. The total number of distal locking screws and their configuration required to obtain adequate stability of the short distal fragment Remains to be a topic of debate. The purpose of this retrospective study was to assess the union and complications associated with distal third tibial fractures which were operated with reamed tibia nail with two versus three distal locking screws. 


\section{Materials and Methods}

A retrospective study was conducted from January 2017 to October 2019 in the Department of Orthopaedics, at a tertiary care center, comparing two versus three distal locking screw options in tibial nail insertion. Fifty-seven patients were included in the study. In 25 patients 2 distal screws were used and in 32 patients 3 distal screws were used. Patients with compound gustillo Anderson 3a, 3b, and 3c fractures were excluded from the study. Patients were followed up to the tibial fracture union (5-12 months with a mean of 7 months). All patients had been given primary treatment in the form of the above-knee slab and limb elevation over Bohler Braun splint, analgesic, and anti-inflammatory medications until the patient was posted for surgery. All patients were posted for surgery only when all preoperative fitness for surgery was obtained, blood investigations were within normal limits and the operative site was clean. Patients were operated on under spinal anesthesia in the supine position.

\subsection{Operative technique}

All the patients were operated on by the same surgeon within 7 days of initial trauma with the standard patella splitting approach for the entry of the tibia nail under all aseptic precautions. Closed reduction was attempted and was successful in all of the cases. Reaming was carried out with solid reamers before inserting the maximum diameter nail possible with the distal locking screws of $4.5 \mathrm{~mm}$ or above used in all of the cases. Distal locking screws were inserted using a freehand technique. Due to the wider medullary canal of the distal tibial metaphysis, any malalignment encountered during reduction, in the mediolateral plane or the anteroposterior plane was tackled by using the poller screw/wire technique. The poller screw/wire, when used was taken out after the completion of locking on both the proximal and distal sites. The configurations of the distal locking screws depended on the available bone distal to the fracture site. Hence the anteroposterior or the mediolateral configurations of screws were used accordingly in each case.

\subsection{Post-operative protocol}

The operative wound was dressed and checked on the 3rd postoperative day, and sutures were removed after 10-14 days. Active knee and ankle range of motion exercises and protected weight-bearing were started from the 3rd post-operative day. The average stay in hospital was 5 days, with the shortest being 3 days and the longest of 10 days. Full weight-bearing was started after 2 weeks from the post-operative period. The patients were followed up clinically and radiologically every month for the first three months and every 3 months thereafter until the radiological union was seen.

\section{Results}

The average age of patients in our study was between 21-56 years with a mean age of 34 years. The male-to-female ratio was approximately 3:1 (42 males and 15 females). The most commonly encountered mode of injury was a road traffic accident $(87.7 \%)$. Of the 57 cases in our study 48 cases were closed injuries, whereas 9 cases were open fractures. Out of these 9 open fractures, five were Gustillo Anderson type I, four were type II. All were operated by the same surgeon. The average time interval between admission and surgery was 36-72 hours for closed injuries and 16-24 hours for open injuries. 25 cases $(43.85 \%)$ had two distal locking screws and 32 cases $(56.14 \%)$ had three. Reaming of the tibia was done in all cases $(100 \%)$. The fracture union rate was $96.49 \%$. Complications resulting from tibial nailing in our study [Figure-1] were superficial wound infection in two cases, pain at screw site (one case), and delayed union in 2 cases.

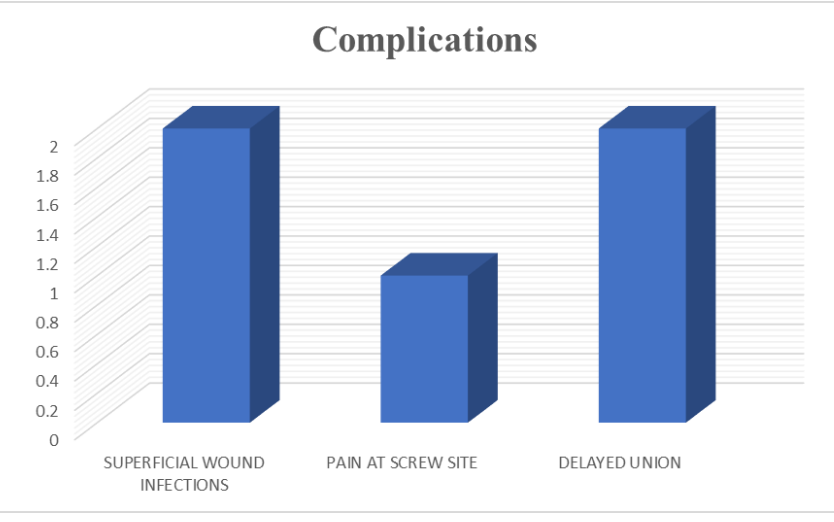

Fig 1: Complications encountered in our study

Delayed union, which was defined as one or two cortex contact seen radiographically at 9 months, occurred in 3.5\% (2 cases) of distal tibial fractures treated with IM nailing [Table-1]. Of these, 1 case had two distal locking screws and the remaining 1 had three. This difference was statistically insignificant ( $p>0.01)$.

Table 1: Details of the patient with delayed union

\begin{tabular}{|c|c|c|}
\hline & Two screw (1 case) & Three screw (1 case) \\
\hline Mode of injury & Road traffic accident & Road traffic accident \\
\hline Type of injury & $\begin{array}{c}\text { Gustillo Anderson type } \\
2\end{array}$ & $\begin{array}{c}\text { Gustillo Anderson type } \\
2\end{array}$ \\
\hline Fracture pattern & $\begin{array}{c}\text { Tibia and fibula } \\
\text { fractured }\end{array}$ & $\begin{array}{c}\text { Tibia and fibula } \\
\text { fractured }\end{array}$ \\
\hline $\begin{array}{c}\text { Treatment } \\
\text { given }\end{array}$ & Dynamisation done & Dynamization done \\
\hline Time to union & 11 months & 12 months \\
\hline
\end{tabular}

Both the delayed union occurred in open fractures and both belonged to Gustillo type 2. Both these delayed unions went on to unite after dynamization was done. Patients were followed up to the radiographical tibial fracture union (5-12 months with a mean of 6 months). A fracture was considered radiographically united when at least 3 out of 4 cortical contacts had occurred. Few of the case illustrations are shown in (figure 2 and 3 ).

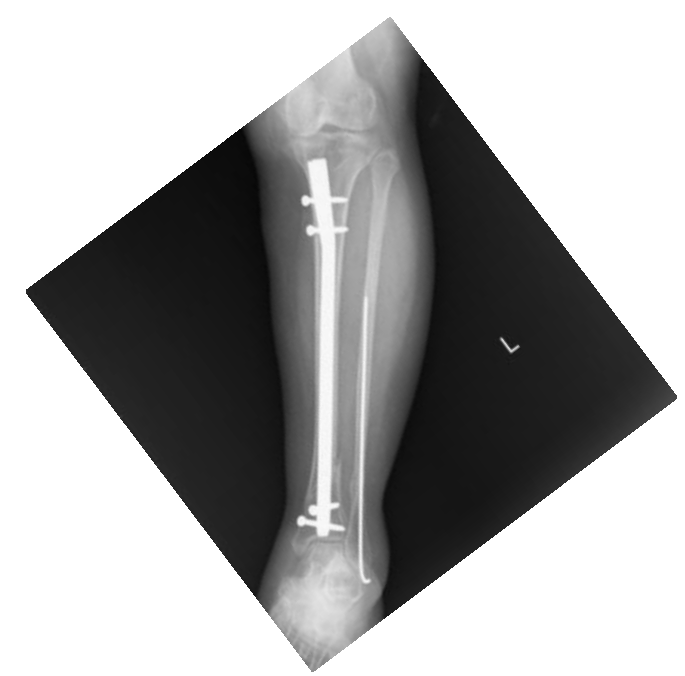

Fig 2: Five month follow up radiograph of the patient who is full weight bearing, operated with two distal screws, showing satisfactory radiological union with no complications. 


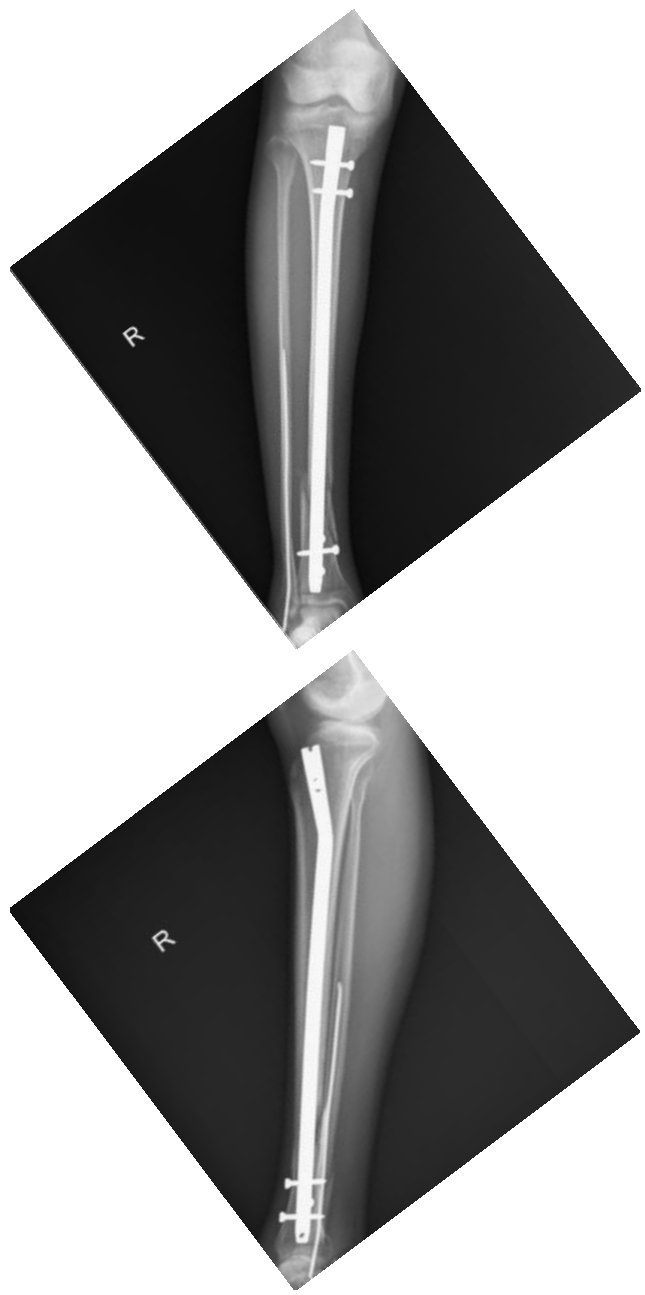

Fig 3: Five and a half month follow up AP and lateral radiographs of the patient who is full weight bearing, operated with three distal screws, showing satisfactory radiological union with no complications.

\section{Discussion}

The best treatment of distal metaphyseal tibial fractures remains a controversial topic of debate. To improve the benefits of clinical outcome of such fractures various modifications of the nail have been introduced. These include the number, direction, and location of the screw holes, which now allows putting an interlocking screw within $5 \mathrm{~mm}$ of the tip of the nail. As a result of these modifications, intramedullary nailing has been used successfully used for the treatment of such fractures. (13-16). Due to the metaphyseal flare of the distal tibia, widening of the intramedullary canal as compared to the diaphysis is created. This results in an insufficient nail-bone contact, and hence the interface between nail, screw, and locking screw number and configuration become important determinants in deciding the overall construct stability. The importance of these determinants is further emphasized by the fact that in the metaphyseal area the cortical purchase of these screws is less. Hence, there are increased stresses on the screws to maintain the reduction and alignment of the fracture fragments.

Our study showed no difference in the clinical and radiological outcomes when two or three distal locking screws were used. All patients were made to fully weight bear from 2 nd post-operative week. Despite this, no postoperative complications such as screw breakage, malunion, delayed union, and non-union were found to be significantly different in either of the groups. This was in accordance with various biomechanical and clinical studies carried out.

Mohammed A et al ${ }^{(17)}$ in their clinical study found high rates of non-union when only one distal locking screw was used and recommended a minimum of two distal screws to be used. In such a scenario, when the insertion of two screws is not possible, an alternative method of fixation is to be used. This result was further confirmed by various biomechanical studies. Lowenberg, DW et al ${ }^{[18]}$ studied the influence of the fracture obliquity on the number and configuration of the distal interlocking screws in their biomechanical study on a saw-bone model. They concluded that when fracture obliquity at the distal tibial metaphysis exceeds $30^{\circ}$ and even with absolute fracture fragment apposition, the number of interlocking screws becomes important to resist shear forces. In such a scenario, the use of a proximal dynamic locking with less than two distal screws should be avoided.

Lowenberg DW et al ${ }^{[19]}$ in their biomechanical study evaluating the influence of number and configuration of the interlocking screws to the inter-fragmentary motion under torsional loading concluded that, irrespective of the fracture obliquity, a minimum of two distal locking screws and one proximal lock in a static mode is required. An extra distal locking screw does not confer any added advantage in resisting the physiological torsional forces. They also concluded that the configuration of the distal locking screws (parallel or perpendicular) did not affect the stability of the construct.

Chan DS et al ${ }^{(20)}$ in their biomechanical study found that three distal screws gave the greatest biomechanical stability compared to two. However, they found sufficient evidence that the amount of stability needed to immediately weight bear was provided even with two distal locking screws.

We recognize some of the limitations in our study. One of them being the small sample size. We have not taken into consideration the fracture obliquity in the outcome. The exact amount of weight transferred onto the weight-bearing limb is not quantified and the distal locking screw configuration is not taken into account in the study.

\section{Conclusion}

Our study showed that there was no statistically significant difference in the clinical, time taken for radiological union and complications such as delayed union and non-union in distal third tibia fractures operated with tibia nailing when two or three distal locking screws were used. Therefore, we conclude that two distal locking screws are a necessity and three are a luxury. The increased distal locking screws do not influence the fracture union.

Conflicting interests: The author(s) declare that they have no conflicting interests".

Acknowledgments and Funding: Nil

Consent: Written informed consent was obtained from the patient for publication purposes.

\section{References}

1. Collins DN, Pearce CE, Mc Andrew MP. Successful use of reaming and intramedullary nailing of the tibia. J Orthop Trauma 4(3):315-322. https ://doi.org/10.1097/00005 1990 131-19900 4030-00014

2. Bone LB, Johnson KD. Treatment of tibial fractures by reaming and intramedullary nailing. J Bone Joint Surg Am 1986;68(6):877-887

3. Coles CP, Gross M. Closed tibial shaft fractures: management and treatment complications. A review of the 
prospective literature. Can J Surg 2000;43(4):256-262.

4. Bedi A, Le TT, Karunakar MA. Surgical treatment of nonarticular distal tibia fractures. J Am Acad Orthop Surg 2006;14:406-416.

5. Vallier HA, Cureton BA, Patterson BM. Randomized, prospective comparison of plate versus intramedullary nail fixation for distal tibia shaft fractures. J Orthop Trauma 2011;25:736-741.

6. Griffin LV, Harris RM, Zubak JJ. Fatigue strength of common tibial intramedullary nail distal locking screws. J Orthop Surg Res 2009;4:11.

7. Bedi A, Le TT, Karunakar MA. Surgical treatment of nonarticular distal tibia fractures. J Am Acad Orthop Surg 2006;14:406-416.

8. Nork SE, Schwartz AK, Agel J, Holt SK, Schrick JL, Winquist RA Intramedullary nailing of distal metaphyseal tibial fractures. J Bone Joint Surg Am 87(6):1213-1221.

9. Im GI, Tae SK. Distal metaphyseal fractures of tibia: a prospective randomized trial of closed reduction and intramedullary nail versus open reduction and plate and screws fixation. J Trauma 2005;59:1219-1223.

10. Freedman EL, Johnson EE. Radiographic analysis of tibial fracture malalignment following intramedullary nailing. Clin Orthop Relat Res 1995;315:25-33

11. Koval KJ, Clapper MF, Brumback RJ, Ellison PS Jr, Poka A, Bathon GH et al. Complications of reamed intramedullary nailing of the tibia. J Orthop Trauma 5:184189

12. Tyllianakis $\mathrm{M}$, Megas $\mathrm{P}$, Giannikas $\mathrm{D}$, Lambiris E. Interlocking intramedullary nailing in distal tibial fractures. Orthopedics 2000;23:805-808

13. Fan CY, Chiang CC, Chuang TY, Chiu FY, Chen THInterlocking nails for displaced metaphyseal fractures of the distal tibia. Injury 2005;36:669-674

14. Gorczyca JT, McKale J, Pugh K, Pienkowski D. Modified tibial nails for treating distal tibial fractures. J Orthop Trauma 2002;16:18-22.

15. Moongilpatti Sengodan M, Vaidyanathan S, Karunanandaganapathy S, Subbiah Subramanian S, Rajamani SG. Distal tibial metaphyseal fractures: does blocking screw extend the indication of intramedullary nailing? ISRN Orthop 2011;4:542623.

16. Kruppa CG, Hoffmann MF, Sietsema DL, Mulder MB, Jones CB. Outcomes after intramedullary nailing of distal tibial fractures. J Orthop Trauma 2015;29(9):e309-e315

17. Mohammed A, Saravanan R, Zammit J, King R. Intramedullary tibial nailing in distal third tibial fractures: distal locking screws and fracture non-union. Int Orthop. 2008 Aug;32(4):547-9. doi: 10.1007/s00264-007-0356-3. Epub 2007 Apr 5. PMID: 17410364; PMCID: PMC2532262.

18. Lowenberg DW, DeBaun MR, Sox-Harris A. Influence of fracture obliquity and interlocking nail screw configuration on interfragmentary motion in distal metaphyseal tibia fractures. Eur J Orthop Surg Traumatol 2020;30:343-350. https://doi.org/10.1007/s00590-019-02553-w

19. Lowenberg DW, DeBaun MR, Behn A, Sox-Harris A. Interlocking screw configuration influences distal tibial fracture stability in torsional loading after intramedullary nailing. Eur J Orthop Surg Traumatol. 2020 Oct;30(7):1205-1213. doi: 10.1007/s00590-020-02686-3. Epub 2020 May 4. PMID: 32367222.

20. Chan DS, Nayak AN, Blaisdell G, James CR, Denard A, Miles J, Santoni BG. Effect of distal interlocking screw number and position after intramedullary nailing of distal tibial fractures: a biomechanical study simulating immediate weight-bearing. J Orthop Trauma 2015;29(2):98-104. doi: 10.1097/BOT.0000000000000195. PMID: 25072288. 